\title{
Confusion, CTCAE 5.0
}

National Cancer Institute

\section{Source}

National Cancer Institute. Confusion, CT CAE 5.0. NCI Thesaurus. Code C146785.

A disorder characterized by a lack of clear and orderly thought and behavior. 